\title{
A size-based approach to quantifying predation on longfin inshore squid Loligo pealeii in the northwest Atlantic
}

\author{
Michelle D. Staudinger*, Francis Juanes \\ Department of Natural Resources Conservation, University of Massachusetts, 160 Holdsworth Way, Amherst, \\ Massachusetts 01003-9285, USA
}

\begin{abstract}
Cephalopods are primary prey to a wide range of predators in global marine ecosystems. Despite their apparent ecological importance, little information exists on size-based predation respective to this taxon. Using long-term food habits and data from population surveys and commercial landings, we quantified size-based patterns of predation respective to 11 species of finfish, elasmobranchs, and marine mammals over ontogenetic scales. General trends of sizeselective and seasonal foraging behavior are also presented for 25 species of predators from the northwest Atlantic Ocean. The functional role of squid was evaluated by contrasting patterns in sizebased predation between squid and fish prey types. Measurements of predator gape morphology and prey body depths ascertained if predators were physically limited when feeding on squid. Additionally, the amount of overlap between natural predators and the commercial fishing industry for squid size resources was estimated. Predation by finfish and elasmobranchs was generally focused on juvenile and sub-adult squid, while marine mammals primarily targeted adults. Consequently, marine mammals had the highest overlap with the commercial fishing industry for squid size resources. All predators exhibited size-selective feeding behavior, and trends persisted over seasonal time periods. Predators fed on a wider range of fish prey sizes than squid and did not appear to be gape limited when feeding on squid; however, large squid were not common in predator diets. Results suggest squid behavior and availability in the environment are paramount in shaping sizebased patterns of predation.
\end{abstract}

KEY WORDS: Size-based predation · Size-selection · Trophic niche breadth · Gape limitation Longfin inshore squid · Loligo pealeii

Resale or republication not permitted without written consent of the publisher

\section{INTRODUCTION}

Predators are opportunistic, switching between prey species on the basis of their absolute and relative availabilities in the environment; however, to some extent all predators are selective (Bax 1998). In marine piscivores, the relationship between predator and prey body size directly influences foraging success and is one of the best indicators of the physical constraints on an individual (Peters 1983, Claessen et al. 2002). Other morphological features that change in proportion to a predator's body size, such as mouth gape, are informa- tive and define the upper size limits of prey consumed both intra- and interspecifically (Juanes 1994, Nilsson \& Bronmark 2000, Juanes et al. 2002). As predators grow, the maximum size of prey consumed generally increases, but diets are often concentrated on, or continue to include, small prey (Juanes \& Conover 1995, Scharf et al. 2000). Few marine predators feed exclusively on the largest prey they possibly can because (1) it is energetically costly to pursue large prey (Scharf et al. 2003), and (2) smaller individuals are exponentially more abundant in marine food webs in comparison to larger ones (Brooks \& Dodson 1965, Rice \& 
Gislason 1996). Accordingly, the total range of prey sizes consumed by a predator depends largely on what it can physically manipulate, what is available in its immediate environment, and how energetically profitable it is to pursue increasingly larger prey.

The range of absolute prey sizes consumed by many marine predators will increase by orders of magnitude as their diets shift from planktivory during early life stages to piscivory as adults. For this reason, an individual's trophic position within its community is more accurately described by body size rather than species (Jennings \& Reynolds 2007). Alternatively, the range of relative prey sizes consumed ontogenetically by a predator, known as its size- or ratio-based trophic niche breadth, often remains constant with predator ontogeny (Pearre 1986, Scharf et al. 2000). Size-based trophic niche breadths are useful for identifying physical limitations on a predator's feeding patterns, provide equivalent measures of resource use among species, and are appropriate for assessing competition for prey size resources (Bethea et al. 2004, Beauchamp et al. 2007).

While much attention has been given to size-based predation by piscivores (Juanes 1994, Mittelbach \& Persson 1998, Manderson et al. 1999, Dorner \& Wagner 2003), little to no information exists on the sizedependent relationships between cephalopods and their predators. Many top predators that are primarily piscivorous also include cephalopods in their diets over different seasonal, spatial, and ontogenetic scales (Stillwell \& Kohler 1982, Clarke 1996, Dawe \& Brodziak 1998, Chase 2002, Staudinger 2006). For example, while cephalopods are virtually absent from predator diets in estuarine environments, there is a transition towards cephalopods in shelf, slope, and open ocean habitats (Smale 1996). Previous studies have focused primarily on the weight contribution of cephalopods to predator diets and have neglected to detail size-based patterns in feeding and behavioral interactions. In studies of food habits in which squid body sizes have been reported, large squid are often prevalent in predator diets (Kohler 1987, Smale 1996, Gannon et al. 1997, Chase 2002, Staudinger 2006). Small squid are rarely reported in diet analyses; consequently, natural mortality rates for paralarval squid are thought to be relatively low in comparison to those of fish (Pierce \& Guerra 1994). If predation pressure is concentrated during the later stages of life, this would suggest that predation may primarily act as a control on population structure and individual life history rather than recruitment success as is common in many species of fish (Claessen et al. 2002, Dorner \& Wagner 2003).

Squid have been described as functionally similar to fish in many aspects of their ecology; their habitat distributions, schooling behaviors, body sizes, and shapes are analogous to those of many fishes (Packard 1972,
Hanlon \& Messenger 1996, Pauly 1998). For these reasons, size-based predation on squid may be comparable to that on fish that occupy analogous trophic roles (e.g. clupeids) (Packard 1972). Conversely, squid possess traits that could make them more susceptible to predation than prey fish. Squid lack hard defensive structures such as spines and bony plates. Squid also have soft, cylindrical body forms that may make larger individuals easier to be engulfed by predators. Optimal diet theory states that predators should select prey that provides the greatest energetic return for the least amount of effort to retain (Stephens \& Krebs 1986, Sih \& Christensen 2001). Additionally, when a higher quality food source becomes more abundant, it should become more important in a predator's diet. The high nutritional value of cephalopods offers predators an added incentive of approximately $20 \%$ more digestible protein per unit body mass than that of fish (Lee 1994). The reward of a higher quality meal may motivate predators to pursue larger sized squid than fish. Currently, we do not know enough about size-dependent relationships between squid and their predators to predict how size, morphology, quality, and availability interact to influence predator selection for squid in comparison to prey fish resources.

Overfishing has altered the trophic structure of marine food webs by systematically removing the largest individuals and depleting predator populations to fractions of their former abundance levels (Jackson et al. 2001, Baum et al. 2003, Myers \& Worm 2003, Ward \& Myers 2005). To replace yields lost by the collapse of more traditional fish stocks, commercial fisheries have increasingly targeted squid and other forage fish (Pauly et al. 2002, FAO 2007). Despite the overfished status of many teuthophagous species, predatory demand on squid populations has been estimated to exceed commercial landings by orders of magnitude and to be equal to or greater than maximum sustainable yield (Buckel et al. 1999, Overholtz et al. 2000). It has been suggested that the short life cycles and high growth rates inherent to cephalopod populations have allowed them to rapidly increase productivity in response to reduced predation pressure (Caddy \& Rodhouse 1998, Dawe \& Brodziak 1998, Piatkowski et al. 2001); however, it is uncertain if squid populations can endure the demands imposed by a community of predators as well as a growing fishing industry. To manage both cephalopods and their predators sustainably, a holistic approach that considers multispecies trophic interactions is crucial. Natural and anthropogenic sources of mortality may inflict opposing or cumulative forces of size-selection on squid populations; therefore, it is also important to evaluate how predation is concentrated relative to fishing pressure (Duplisea 2005). 
The overall objective of this paper is to provide baseline information on size-dependent relationships between one of the most ecologically and commercially valuable species of cephalopod in the northwest Atlantic ecosystem, longfin inshore squid Loligo pealeii, and its predators. Using data on long-term food habits, population survey data, and commercial landings information, we (1) quantify how size-based patterns of predation on squid vary among predator species, over ontogenetic scales, and during seasonal time periods; (2) contrast the functional role of squid in comparison to that of other forage fish; (3) evaluate morphological characteristics in squid and teuthophagous predators that constrain size-dependent relationships; and (4) estimate the amount of overlap between natural predators and the commercial fishing industry for squid size resources.

\section{MATERIALS AND METHODS}

Diet data. Predator and prey body size data were obtained from several sources. The largest data set was collected as part of long-term fishery-independent population surveys conducted by the Northeast Fisheries Science Center (NEFSC). Surveys were con- ducted during the winter, spring, and fall seasons and spanned the region from Cape Lookout, North Carolina, northward to waters off Nova Scotia, Canada. Survey details can be found in the reports by Azarovitz (1981) and the Northeast Fisheries Center Survey Working Group (NEFC 1988). Data sets on finfish and marine mammal diets, collected by several independent authors, were also included (Gannon et al. 1997, Staudinger 2006, K. Ampela unpubl. data). Predator names, sample sizes, dates of food habits collection, and geographic ranges are listed in Table 1.

The majority of squid mantle lengths (ML) were measured directly using intact specimens found in predator stomachs. If prey remains were highly digested, the chitinous gladius (or pen) was used as an equivalent for ML. In several data sets, squid beaks were recovered during diet analyses, and original body size was reconstructed using predictive equations relating the lower rostral length of the lower beak to ML (Clarke 1986, Staudinger et al. 2009). Grey seal Halichoerus grypus diets were collected from haul-out sites on Muskeget and Monomoy Islands. The majority of seals at these sites were sub-adults and adults of mixed sex and were estimated to range from 90 to $275 \mathrm{~cm}$ in total length (K. Ampela pers. comm.). Because squid remains were collected from scat, body

Table 1. Predators of longfin inshore squid Loligo pealeii. $\mathrm{n}=$ indicates sample sizes of squid lengths, bolded values indicate predators included in quantile regression analyses. a: Cape Lookout, North Carolina to Nova Scotia, Canada; b: Massachusetts; c: North Carolina to New York; d: New Jersey to Massachusetts

\begin{tabular}{|c|c|c|c|c|c|}
\hline Common name & Scientific name & $\mathrm{n}$ & Yr & Region & Source \\
\hline Atlantic cod & Gadus morhua & 5 & 1991-2004 & a & \\
\hline Atlantic halibut & Hippoglossus hippoglossus & 3 & 1991-2004 & a & \\
\hline Atlantic mackerel & Scomber scombrus & 45 & 1991-2004 & a & \\
\hline Black sea bass & Centropristis striata & 7 & 1991-2004 & $\mathrm{a}$ & \\
\hline Bluefish & Pomatomus saltatrix & 267 & 1991-2004 & $\mathrm{a}, \mathrm{d}$ & Staudinger (2006) \\
\hline Clearnose skate & Raja eglanteria & 2 & 1991-2004 & $\mathrm{a}$ & \\
\hline Fourspot flounder & Paralichthys oblongus & 136 & 1991-2004 & $\mathrm{a}$ & \\
\hline Goosefish & Lophius americanus & 96 & 1991-2004 & $\mathrm{a}, \mathrm{d}$ & Staudinger (2006) \\
\hline Grey seal & Halichoerus grypus & 84 & $2004-2007$ & $\mathrm{~b}$ & K. Ampela (unpubl. data) \\
\hline Little skate & Leucoraja erinacea & 9 & 1991-2004 & a & \\
\hline Long-finned pilot whale & Globicephala melas & 497 & 1989-1991 & $\mathrm{C}$ & Gannon et al. (1997) \\
\hline Offshore hake & Merluccius albidus & 2 & 1991-2004 & a & \\
\hline Pollock & Pollachius virens & 8 & 1991-2004 & a & \\
\hline Red hake & Urophycis chuss & 11 & 1991-2004 & a & \\
\hline Sea raven & Hemitripterus americanus & 19 & 1991-2004 & a & \\
\hline Silver hake & Merluccius bilinearis & 82 & 1991-2004 & $\mathrm{a}, \mathrm{d}$ & Staudinger (2006) \\
\hline Smooth dogfish & Mustelus canis & 255 & 1991-2004 & $\mathrm{a}$ & \\
\hline Spiny dogfish & Squalus acanthias & 615 & 1991-2004 & $\mathrm{a}$ & \\
\hline Spotted hake & Urophycis regia & 58 & 1991-2004 & a & \\
\hline Striped bass & Morone saxatilis & 28 & 1991-2004 & $\mathrm{a}$ & \\
\hline Summer flounder & Paralichthys dentatus & 277 & 1991-2004 & $\mathrm{a}, \mathrm{d}$ & Staudinger (2006) \\
\hline Weakfish & Cynoscion regalis & 25 & 1991-2004 & $\mathrm{a}$ & \\
\hline White hake & Urophycis tenuis & 3 & 1991-2004 & a & \\
\hline Windowpane & Scophthalmus aquosus & 5 & 1991-2004 & $\mathrm{a}$ & \\
\hline Winter skate & Leucoraja ocellata & 32 & 1991-2004 & a & \\
\hline
\end{tabular}


lengths could not be confirmed for individual seals; therefore, only prey length data were used for this predator species.

Size-based patterns of predation. To identify the sizes of squid most recurrent in predator diets and to determine at which stage of each squid's life cycle sizespecific predation was most prevalent, absolute body size relationships between squid and their predators were evaluated using least squares and quantile regression techniques. Individual predator species were evaluated by graphing predator-prey length data as scatter-plots. Quantile regression was used to estimate the rate of change in the lower and upper bounds of predator-prey body size distributions respective to each predator species and over a wide range of predator body sizes (Scharf et al. 1998a, Cade et al. 1999, Scharf et al. 2000, Cade \& Noon 2003). Estimated lower and upper bounds were represented either by 5th/95th, 10th/90th, or 25th/75th quantiles, depending on sample size restrictions as suggested by Scharf et al. (1998a). Lastly, mean predator-prey body size relationships were estimated using ordinary least-squares regression.

Relative predator-prey body size relationships were used to quantify size-based trophic niche breadths of individual predator species and evaluate interspecific competition for squid size resources. Relative body sizes were calculated by dividing the total length of each squid (length of squid mantle and arms, tentacles excluded [Staudinger et al. 2009]) by its corresponding predator length (PL). Resulting predator-prey size ratios were examined as relative and cumulative frequency distributions to determine the percentages of relatively small $(<20 \%$ relative body size), medium or intermediate $(20 \% \geq$ and $<50 \%$ relative body size), and large ( $\geq 50 \%$ relative body size) squid in each predator's overall diet.

Size-based trophic niche breadths were determined by graphing relative size ratios as the dependent variable against predator size (independent variable) and displayed as scatter-plots (Scharf et al. 2000, Juanes 2003). Quantile regression was then used to estimate the lower and upper bounds of these scatter-plots. The 10th and 90th quantiles were chosen to evaluate all predator species because they adequately described the shapes of relative body-size distributions while remaining conservative even when sample size restrictions (Scharf et al. 1998a) were not strictly adhered to. This methodology ensured that estimates of size-based trophic niche breadths were standardized and comparable across predator species. An F-test was used to detect differences between the lower and upper bound slopes and determine if size-based trophic niche breadths were parallel, converging, or diverging (Scharf et al. 2000, Juanes 2003). No difference between lower and upper bound slopes indicated parallel size-based trophic niche breadths and hence a constant range of relative squid sizes consumed with predator ontogeny. Significant differences between slopes indicated either diverging and expanding, or converging and contracting size-based trophic niche breadths.

The mean size-based trophic niche breadth (TNB) respective to each predator was calculated using Eq. (1):

$$
T N B=\frac{\sum_{i=1}^{i=n}\left[\left(m_{90}\right)\left(P L_{i}\right)+\left(b_{90}\right)\right]-\left[\left(m_{10}\right)\left(P L_{i}\right)+\left(b_{10}\right)\right]}{n}
$$

where $i=$ an observation of predator length $(P L), n=$ the total number of observed species-specific predatorprey length combinations; $m=$ the slope, and $b=$ the intercept calculated for the 10th and 90th quantiles of relative predator-prey size ratios regressed on predator size in each predator data set. Size-based trophic niche breadths were then plotted as box and whisker plots and ordered from smallest to largest.

To determine if predators were feeding opportunistically or exhibiting size-selection on squid, size distributions of longfin inshore squid populations available in the environment were compared to the distributions of squid lengths recovered from predator diets. If a predator was feeding opportunistically, the distribution of squid lengths in its diet was similar to the distribution of lengths in the environment. Negative sizeselection occurred if predators had greater frequencies of relatively smaller squid lengths in their diets compared to lengths available in the environment. Conversely, positive size-selection was supported if a greater proportion of a predator's diet was composed of relatively larger squid lengths than were most abundant in the environment.

Squid population data were collected as part of the NEFSC bottom-trawl survey and subset to correspond to the same time period (from 1991 to 2004) during which the majority of diet data were collected. Squid lengths were grouped into $1 \mathrm{~cm}$ ML increments to generate frequency distributions. All population and diet length distributions were positively skewed and in violation of normality; therefore, the KolmogorovSmirnov test was chosen to contrast differences (Zar 1984, Sokal \& Rohlf 1995) and performed using the NPAR1WAY command in SAS (SAS 2003). When significant differences between predator diets and squid population data were detected, visual inspections of length frequency distributions were conducted to ascertain if negative or positive size-selection was occurring. Seasonal trends in size-selection were also evaluated for winter, spring, and fall; population data were not available for summer. 
Functional roles of squid and forage fish. Predator diets in the northwest Atlantic contain a greater diversity of prey fish species than cephalopod species; however, this does not necessarily mean that a greater range of fish prey sizes will be consumed. Size-based trophic niche breadths respective to squid and forage fish were compared to evaluate if predators were exploiting the 2 prey types similarly. Body size data on prey fish were collected as part of the food-web dynamics program (NEFSC) and correspond to the same predators and time periods that were used for calculations of squid size-based trophic niche breadths.

To determine how squid ranked on the spectrum of potential body shapes available to predators, measurements of squid body depth (BD) and width (BW) were compared with those of several common prey fish found throughout the northwest Atlantic. Longfin squid were collected from coastal waters off Massachusetts by otter-trawl on the RV 'Gemma' between May and August in 2007. Measurements of squid BD and BW were made at the maximum points on the mantle with digital calipers to the nearest $0.01 \mathrm{~mm}$. The resulting relationship between squid BD and total length was compared with butterfish Peprilus triacanthus, sand lance Ammodytes americanus, and Atlantic herring Clupea harengus, using previously published morphometric equations (Scharf et al. 1998b). Sand lance and butterfish were representative of the minimum and maximum BDs, respectively, of prey fish available to predators in the northwest Atlantic (Ménard et al. 2006), and Atlantic herring was assumed to most closely resemble squid in overall body form (Packard 1972).

Morphological constraints on size-dependent relationships. If predators are gape limited, prey BD may be influential in constraining foraging behavior (Nilsson \& Bronmark 2000). Relationships among squid BD and BW, PL, and predator gape size were examined to determine if predators were feeding near their physical limits over ontogeny. Gape sizes were assessed from specimens of Atlantic mackerel Scomber scombrus, fourspot flounder Paralichthys oblongus, smooth dogfish Mustelus canis, spotted hake Urophycis regia, and summer flounder Paralichthys dentatus collected on the NEFSC 2008 spring bottom-trawl survey. All other predator gape relationships were adapted from Scharf et al. (2000). Gape height (GH) was measured as the maximum linear distance from the upper and lower jaws with the mouth stretched open. Gape width (GW) was measured as the linear distance from the corners of the stretched open mouth. Squid length data were converted to BD and BW using equations developed from the data collected above. Relationships between the limiting squid body metric and the limit- ing predator gape dimension were plotted as dependent variables against corresponding PLs (independent variables).

Overlap between predators and the commercial fishing industry. To evaluate whether predators were exploiting similar squid size resources as the fishing industry, squid lengths from predator diets were compared with those landed commercially. Predator diet data (Table 1) were pooled and grouped into $1 \mathrm{~cm}$ increments. Commercial data were obtained from the most recent stock assessment (NEFSC 2002) and subset to match the primary period during which predator diet information was collected (from 1991 to 2004). In addition to testing differences of location and distribution using a Kolmogorov-Smirnov test, the degree of overlap between predators and the fishing industry was estimated by calculating the overlapping area under the 2 distribution curves.

\section{RESULTS}

\section{Size-based patterns of predation}

Juvenile and sub-adult squid (from 2 to $10 \mathrm{~cm} \mathrm{ML}$ ) were most important to finfish and elasmobranch predators while adults ( $\geq 15 \mathrm{~cm} \mathrm{ML)} \mathrm{dominated} \mathrm{(>90 \% )}$ the diets of marine mammals (Fig. 1). The mean size of all predators sampled was $128 \mathrm{~cm}$, and the vast majority were $\leq 100 \mathrm{~cm}$.

Of the 25 predators listed in Table 1, 10 species had sample sizes large enough to meet minimum requirements suggested for conducting quantile regression analysis $(n \geq 40)$. Estimations of the lower bound (from -0.01 to 0.35 ), mean (from -0.03 to 0.51 ), and upper bound (from -0.09 to 0.67 ) regression slopes for absolute body size relationships between squid and their predators spanned several orders of magnitude and ranged from negative to positive. With the exception of Atlantic mackerel, all predators exhibited lower bound slopes that were moderate in comparison to mean and upper bound slopes (Table 2).

Small predators $(<40 \mathrm{~cm}$ PL) such as Atlantic mackerel, fourspot flounder, and silver and spotted hakes exhibited rapid and simultaneous increases in the minimum and maximum sizes of squid in their diets (Fig. 2). Consequently, a narrow range of squid lengths was consumed by small predators at any given size, but predation shifted across multiple squid life stages (e.g. juvenile to sub-adult) as predators grew. In contrast, large predators such as goosefish, pilot whales, and smooth and spiny dogfish maintained relatively constant and broad ranges of squid sizes in their diets at all stages of growth (Fig. 2). The 2 intermediate sized predators, bluefish and summer flounder, exhibited the greatest 
variation between the minimum and maximum size of squid in their diets. Both species expanded the overall distribution of squid sizes in their diets with ontogeny, although summer flounder's upper limit (25 cm ML) was much higher than that of bluefish (15 cm ML). Similar shapes in predator-prey body size distributions were observed among closely related predators (e.g. dogfish), yet the limits of size-based predation were highly species-specific. For example, the onset of squid predation by spiny dogfish (25 cm PL) occurred at much smaller sizes in comparison to that by smooth dogfish (50 cm PL).

Most predators consumed squid that were $<30 \%$ relative to their own body sizes, and diets were concentrated on squid within a relative size range (from 10 to $20 \%$ ). The dominant size class in each predator's overall diet varied widely, ranging from $<10 \%$ in pilot whales to $40 \%$ in fourspot flounder and spotted hake (Fig. 3). Goosefish diets contained the greatest diversity and largest (up to $84 \%$ ) relative squid sizes of all predators examined. Some predators (e.g. summer flounder) displayed wide distributions of relative squid sizes in their diets, while others (e.g. Atlantic mackerel) exhibited definitive peaks, after which the frequency of larger relative body sizes declined steeply (Fig. 3).

Parallel size-based trophic niche breadths were most common among squid predators (Table 3 \& Fig. 4). Spiny dogfish was the only predator evaluated to exhibit a converging size-based trophic niche breadth, and silver hake was the only predator exhibiting a diverging size-based trophic niche breadth. Visual inspection of several scatter-plots of relative body size suggests diverging (e.g. spotted hake and summer flounder) and converging (e.g. bluefish and goosefish) size-based trophic niche breadths, although differences between the lower and upper bound slopes were not statistically significant.

Comparisons between squid length distributions from population surveys and prey lengths recovered from predator diets determined that all predators were size-selective towards squid ( $D$ statistics were $\geq 0.89$; $\mathrm{p}$-values were $<0.0001)$. Atlantic mackerel was the only species to display negative size-selection. All other predators exhibited positive size-selection, which was most pronounced in the 2 species of marine mammals (Fig. 5). Trends of positive size-selection also persisted seasonally ( $D$ statistics were $\geq 0.36$; $\mathrm{p}$-values were $\leq 0.006$ ). The largest differences were detected during spring, and secondarily during the winter.

\section{Morphological constraints on size-dependent relationships}

The relationship between squid BW and body length $\left(\mathrm{BW}=0.154 \mathrm{ML}+0.680, \mathrm{r}^{2}=0.94, \mathrm{n}=61, \mathrm{p}<0.0001\right)$ increased at a slightly greater rate in comparison to the
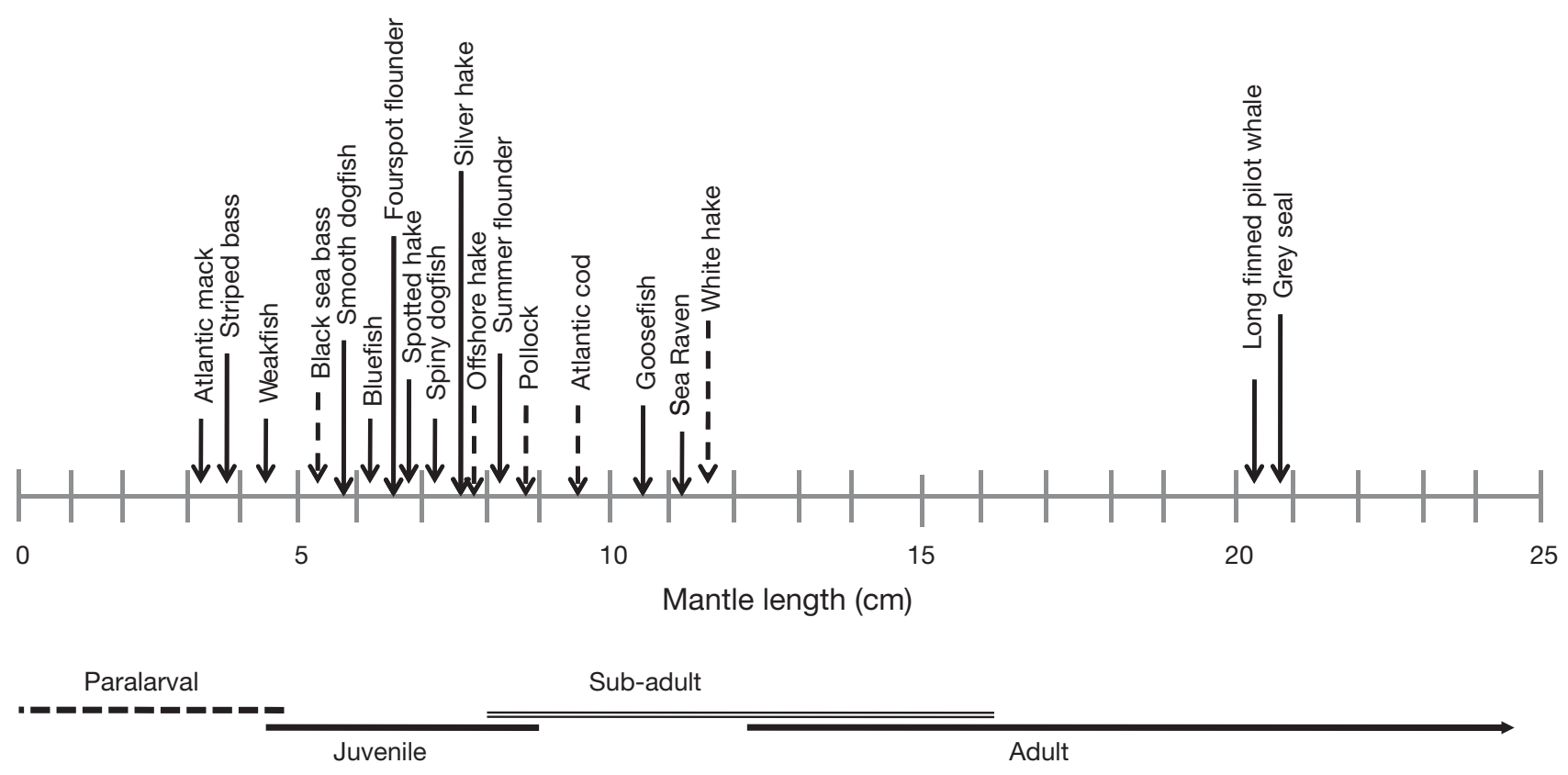

Life stage

Fig. 1. Loligo pealeii. Community spectrum of predation over the life span of longfin inshore squid. Arrows point to the mean size of squid consumed by each predator species. Dashed lines indicate predators with sample sizes $\leq 10 \mathrm{~cm}$. Predator scientific names are listed in Table 1. Squid life stages are approximated to mantle lengths reported by Jacobson (2005) 
relationship between squid $\mathrm{BD}$ and body length $(\mathrm{BD}=$ $0.148 \times \mathrm{ML}+0.581, \mathrm{r}^{2}=0.92, \mathrm{p}<0.0001$ ), but the difference between slopes was not significant.

Predator gape sizes measured in the present study (Table 4) and previously by Scharf et al. (2000) were much greater than squid BD and BW. Consequently, most predators did not appear to be gape limited when feeding on squid. Silver hake and spotted hake were the only predators found to target squid at or near their assumed physical limit and over ontogenetic scales; large silver hake even appeared to consume squid that were beyond their estimated gape (Fig. 6). At small predator body sizes, spiny dogfish consumed squid that were comparable in depth to the span of their gape. No squid size data were reported for body sizes $<25 \mathrm{~cm}$ PL, suggesting that spiny dogfish may be gape limited below this size. After approximately $50 \mathrm{~cm}$ PL, spiny dogfish gapes expanded more rapidly than the squid sizes they were feeding on, and spiny dogfish no longer appeared to be gape limited.

\section{Functional roles of squid and forage fish}

Squid body shapes were intermediate in butterfish and sand lance and changed at a more moderate rate in comparison to that of Atlantic herring (Fig. 7). This suggests that squid's window of vulnerability to predation would be protracted in comparison to the majority of forage fish common throughout the northwest Atlantic. Predators consumed a smaller range of relative squid sizes in comparison to forage fish; however, mean trophic niche breadths for the 2 prey types differed only by about a $10 \%$ margin in the majority of predators (Fig. 8). Goosefish, silver hake, and dogfish were the few predators that exploited considerably larger relative size ranges of fish prey sizes (from 20 to $50 \%$ greater) in comparison to squid.

\section{Overlap between predators and the commercial fishing industry}

The commercial fishing industry harvested significantly larger squid $(D=0.431, \mathrm{p}<0.0001)$ than were targeted by predators. The total estimated overlap between harvested and consumed lengths was $23 \%$ and peaked between 9 and $16 \mathrm{~cm} \mathrm{ML} \mathrm{(Fig.} \mathrm{9).} \mathrm{Diet}$ data were partitioned by the 3 major taxonomic predator groups-finfish, elasmobranchs, and marine mammals-and overlap with the fishing industry was calculated for each group. Marine mammals had the greatest amount of overlap (17\%) with the commercial fishery for squid size resources (Fig. 9). Finfish and

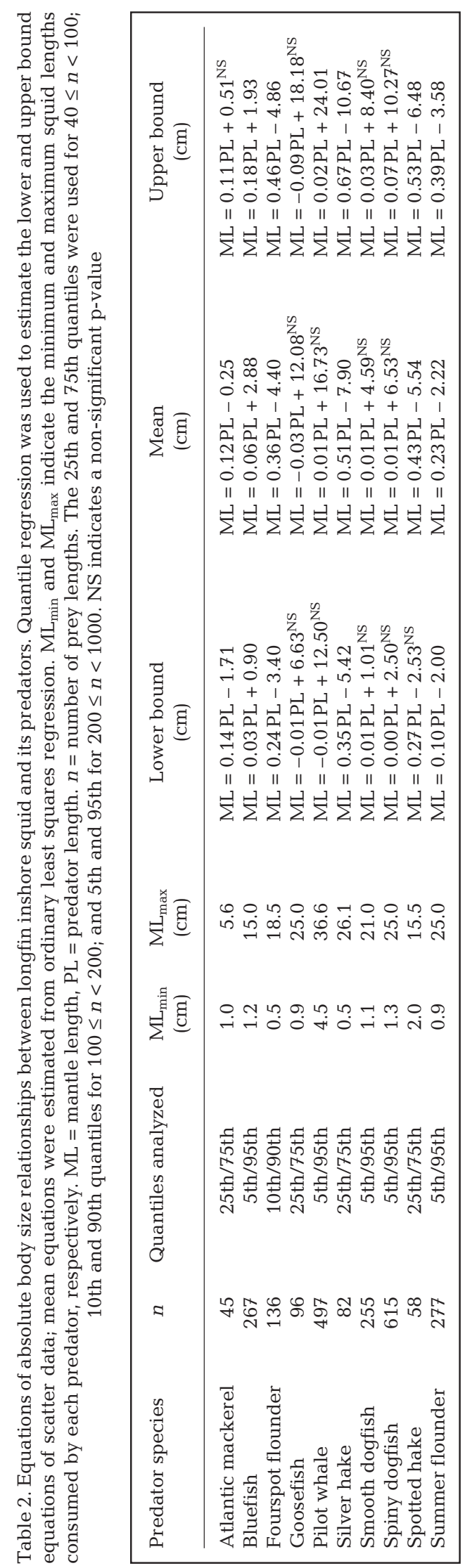



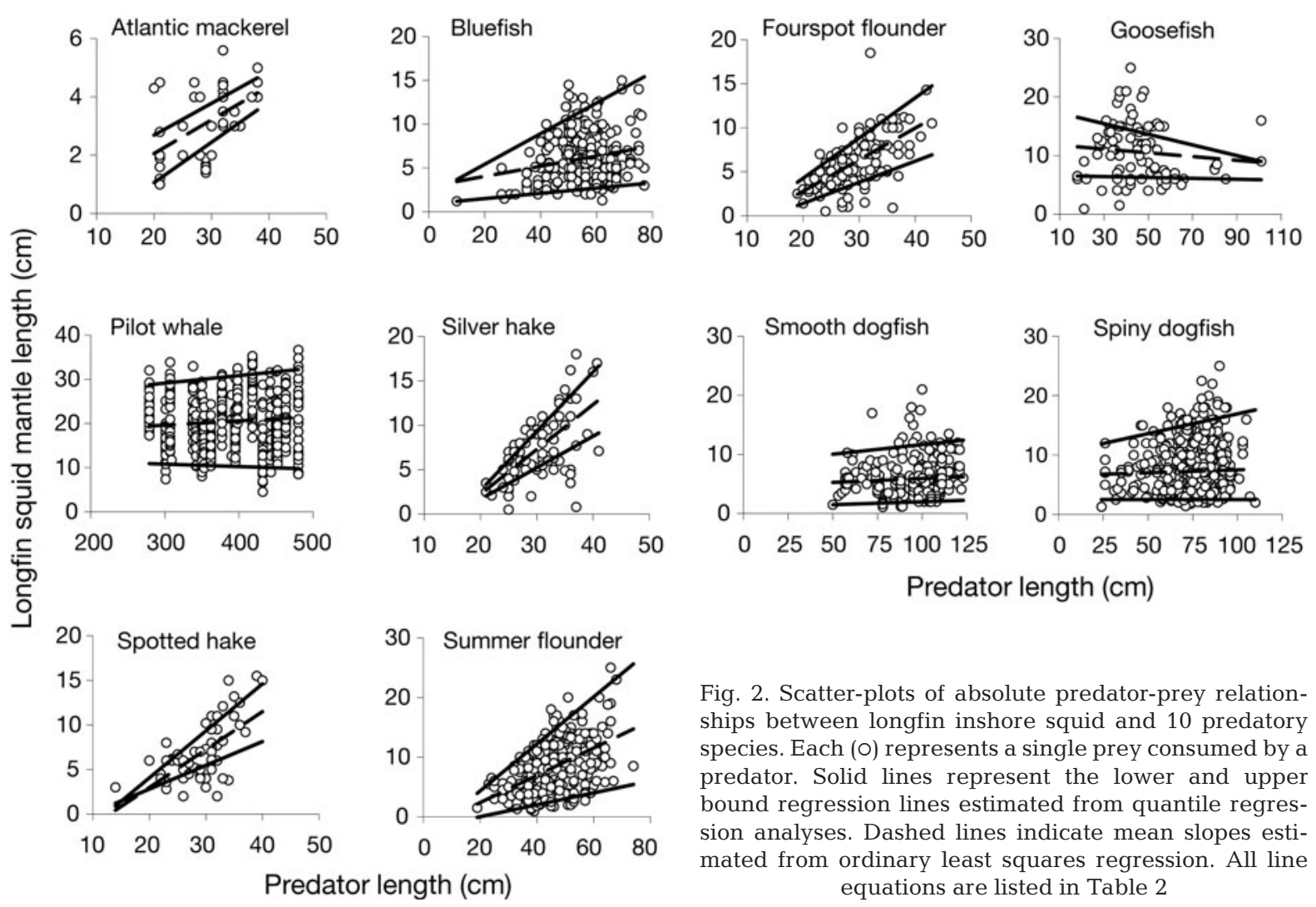

Fig. 2. Scatter-plots of absolute predator-prey relationships between longfin inshore squid and 10 predatory species. Each (O) represents a single prey consumed by a predator. Solid lines represent the lower and upper bound regression lines estimated from quantile regression analyses. Dashed lines indicate mean slopes estimated from ordinary least squares regression. All line equations are listed in Table 2
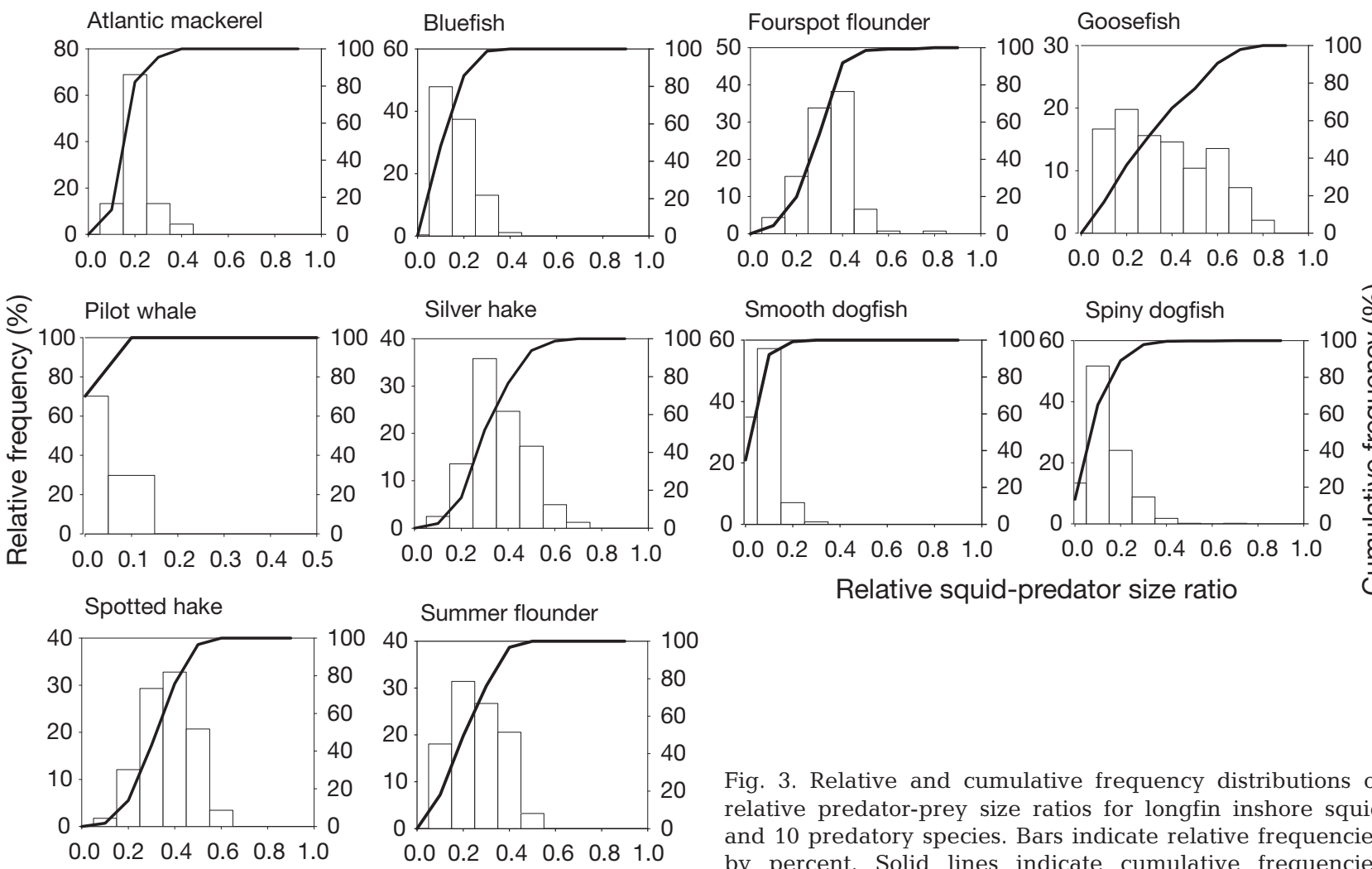

Relative squid-predator size ratio

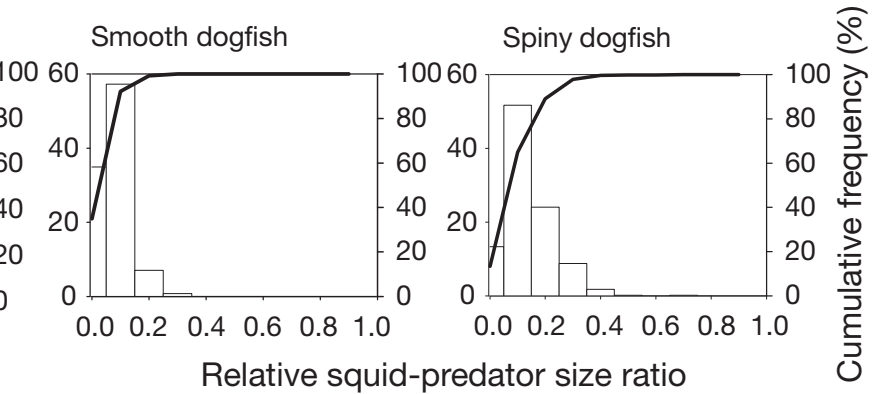

Fig. 3. Relative and cumulative frequency distributions of relative predator-prey size ratios for longfin inshore squid and 10 predatory species. Bars indicate relative frequencies by percent. Solid lines indicate cumulative frequencies by percent 
elasmobranchs were nearly equal in their overlap with the fishery but progressively less than marine mammals (11\% and $9 \%$, respectively).

\section{DISCUSSION}

Although it is well known that predation is the dominant force structuring squid populations in the northwest Atlantic (Buckel et al. 1999, Overholtz et al. 2000), information on size-dependent relationships between squid and their predators has been scarce. The results provided in this study shift from the broad perspective of community down to individual species and represent the most comprehensive evaluation of sizebased predation on a cephalopod species conducted to date.

Size-based feeding patterns on longfin inshore squid varied widely among teuthophagous predators. Maximum squid sizes exhibited the greatest rates of change both within predator species and interspecifically. Teuthophagous predators consumed a narrower range of squid body sizes than were previously reported when all prey types (e.g. crustaceans, fish) were included in size-based diet analyses (Scharf et al. 2000, Ménard et al. 2006). Given the fact that our analyses were limited to a single prey species, this result is not completely unexpected. However, it is noteworthy that the contracted ranges of squid sizes found in predator diets were largely shaped by ontogenetic changes in the minimum size of squid consumed. Rates of change in minimum prey sizes were also greater than have been found in piscivorous predators (Scharf et al. 2000, Ménard et al. 2006).

Small teuthophagous predators (e.g. mackerel, hakes, and flounders) increased both the minimum and maximum sizes of squid in their diets with growth and generally consumed narrow ranges of prey sizes. Consequently, size-based predation by small predators has the potential to fluctuate widely with variations in year-class strength and overall demographic structure. Larger predators such as dogfish and pilot whales targeted a comparatively wide range of squid sizes and exhibited little to no change in the overall sizes of squid in their diets. Accordingly, size-based patterns in predation by these species would remain relatively consistent on all targeted squid life stages regardless of the sizecomposition of predator populations.

With the exception of silver hake and spiny dogfish, size-based trophic niche breadths of teuthophagous predators did not show significant trends of expansion or contraction. This is in contrast to the findings of Scharf et al. (2000) who found an increasing tendency towards narrowing trophic niche breadths in progres-

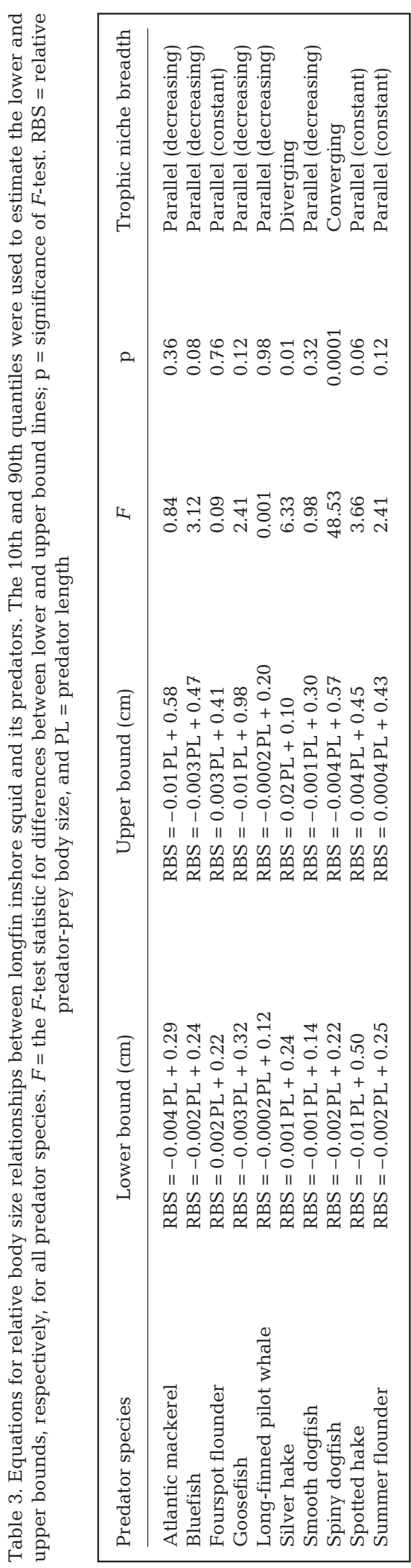



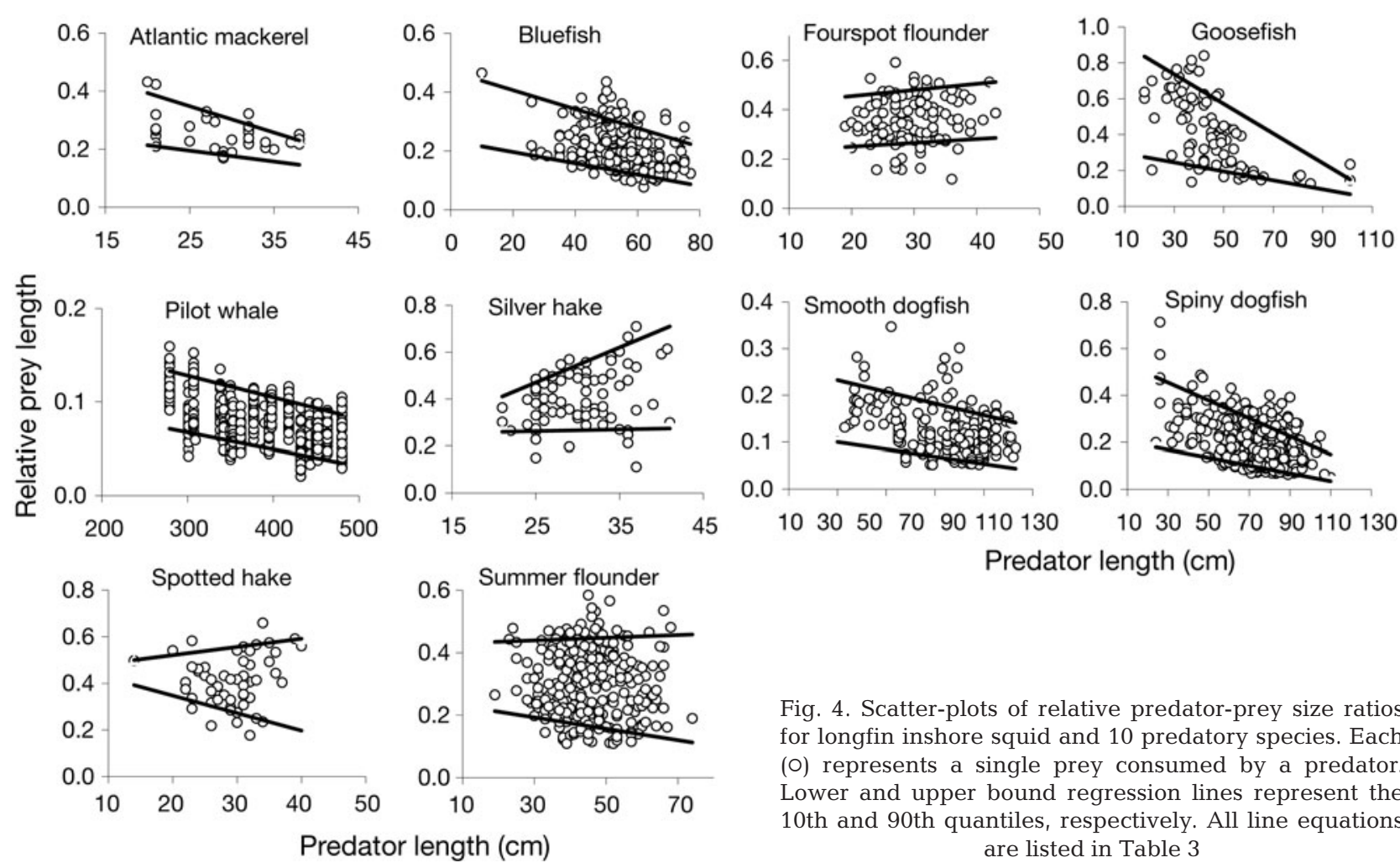

Fig. 4. Scatter-plots of relative predator-prey size ratios for longfin inshore squid and 10 predatory species. Each (O) represents a single prey consumed by a predator. Lower and upper bound regression lines represent the 10th and 90th quantiles, respectively. All line equations are listed in Table 3
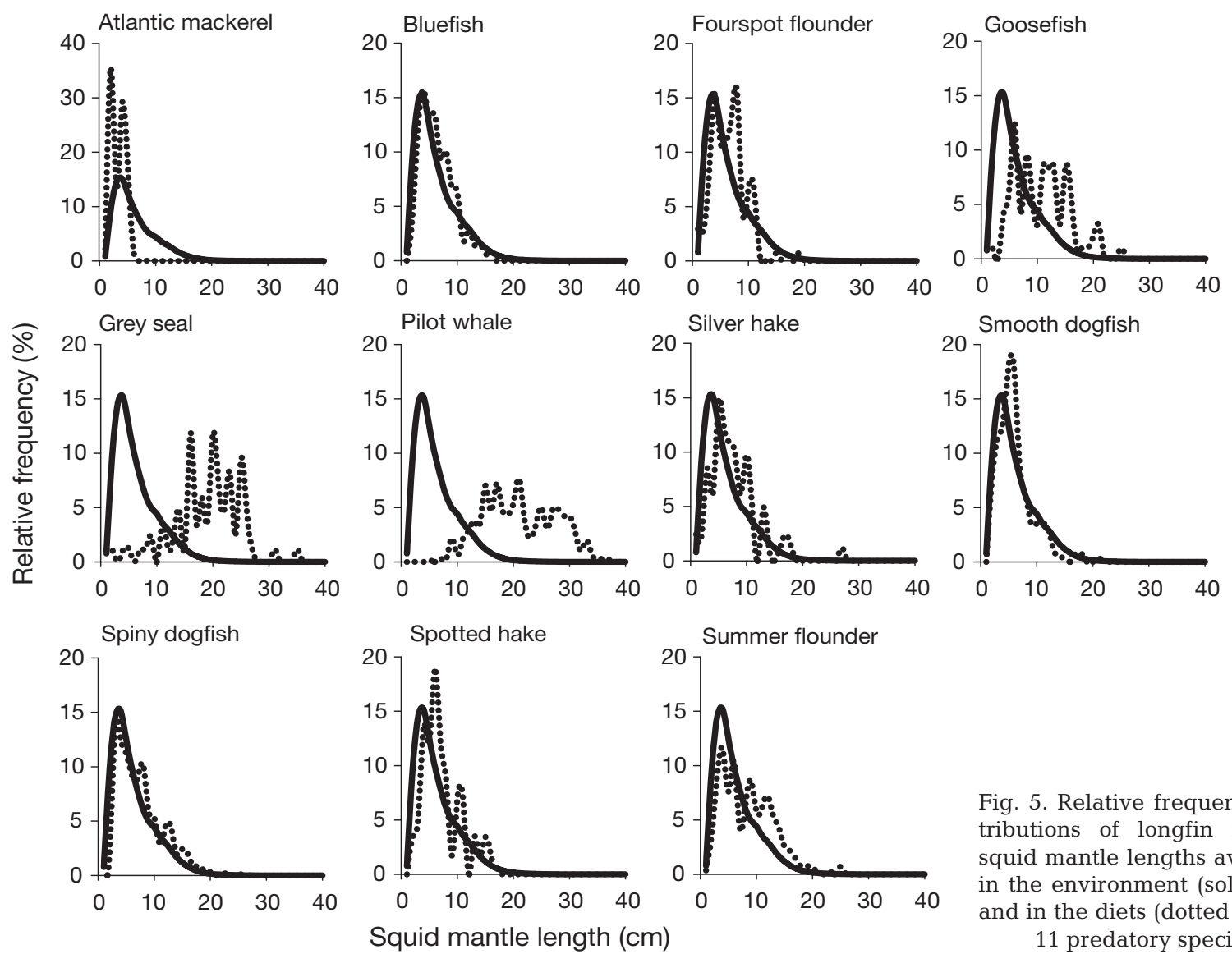

Fig. 5. Relative frequency distributions of longfin inshore squid mantle lengths available in the environment (solid line) and in the diets (dotted line) of 11 predatory species 
sively larger piscivorous predators. Interspecific comparisons of mean size-based trophic niche breadths indicated high correspondence among predators for squid resources. Notable exceptions on both ends of the spectrum were goosefish and pilot whales. Species that co-occur will compete more directly; however, the high amount of overlap observed for squid size resources was probably not limiting to predators since many populations are separated temporally and spatially on the shelf (Bethea et al. 2004). Relative frequency distributions and predator-prey body size relationships determined that the relative size class of squid favored in individual predator diets was highly species specific and varied even among closely related species (e.g. fourspot and summer flounders). Differences among predators were likely shaped by morphological variations, foraging tactics (e.g. lie-and-wait, active), habitat associations, and swimming abilities (Scharf et al. 2000).
Table 4. Linear regression equations for predator length (PL) to gape width (GW) and gape height $(\mathrm{GH})$ for Atlantic mackerel, fourspot flounder, smooth dogfish, spotted hake, and summer flounder. All lengths were measured in $\mathrm{cm}$. All regression equations were highly significant $(p<0.0001)$

\begin{tabular}{|lccc|}
\hline Predator & $\mathrm{n}$ & Equation & $\mathrm{r}^{2}$ \\
\hline Atlantic mackerel & 32 & $\mathrm{GH}=0.117 \mathrm{PL}+0.334$ & 0.86 \\
& & $\mathrm{GW}=0.094 \mathrm{PL}+0.188$ & 0.67 \\
Fourspot flounder & 24 & $\mathrm{GH}=0.156 \mathrm{PL}-0.795$ & 0.93 \\
& & $\mathrm{GW}=0.116 \mathrm{PL}-0.161$ & 0.84 \\
Smooth dogfish & \multirow{2}{*}{35} & $\mathrm{GH}=0.060 \mathrm{PL}-0.753$ & 0.93 \\
& & $\mathrm{GW}=0.065 \mathrm{PL}-0.253$ & 0.96 \\
Spotted hake & \multirow{2}{*}{40} & $\mathrm{GH}=0.092 \mathrm{PL}-0.014$ & 0.88 \\
& & $\mathrm{GW}=0.118 \mathrm{PL}-0.403$ & 0.96 \\
Summer flounder & \multirow{2}{*}{37} & $\mathrm{GH}=0.130 \mathrm{PL}-0.195$ & 0.95 \\
& & $\mathrm{GW}=0.114 \mathrm{PL}-0.261$ & 0.96 \\
\hline
\end{tabular}
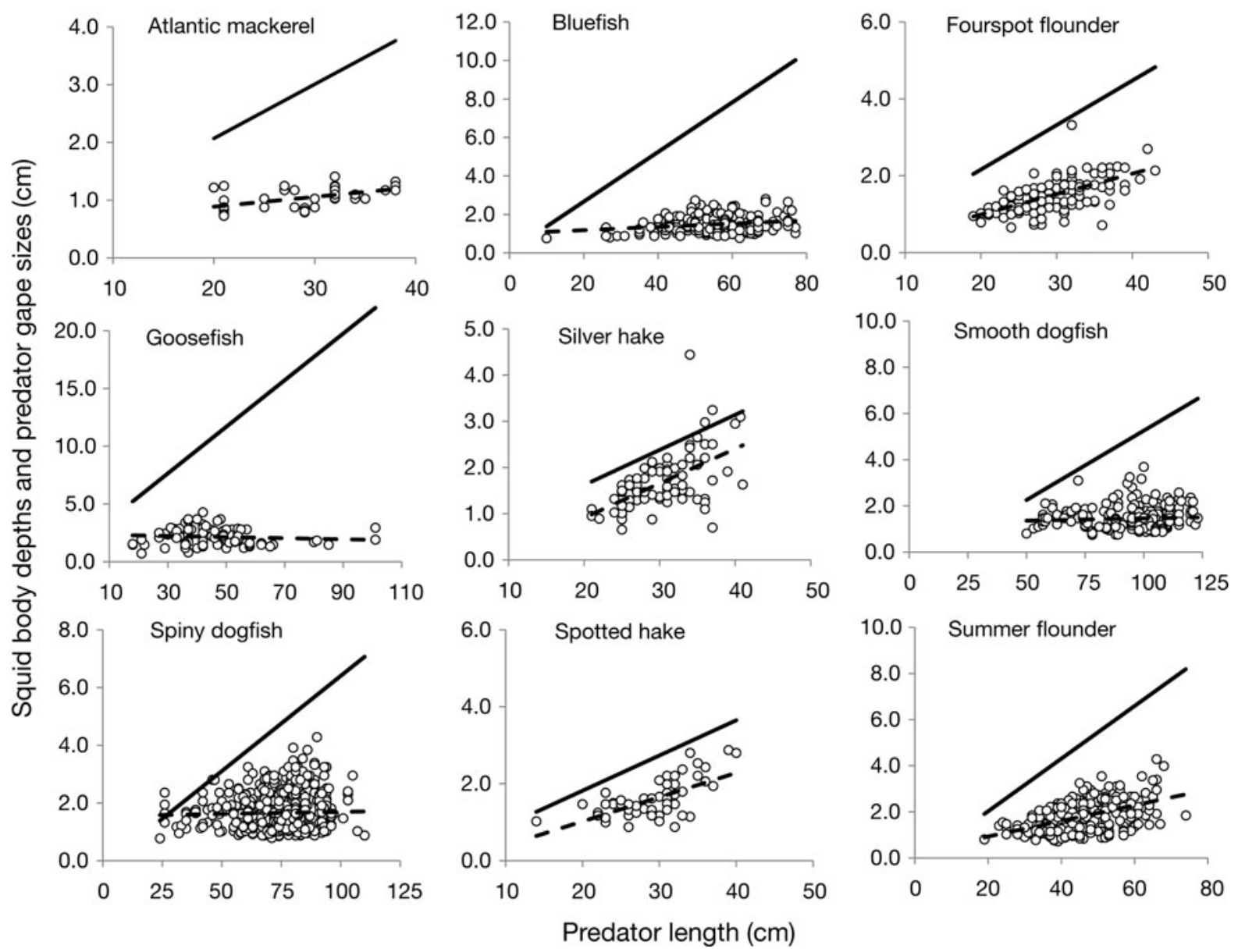

Fig. 6. Scatter-plots of longfin inshore squid body depth (BD) versus length of 9 predatory species. Each (O) represents a single squid consumed by a predator. All relationships for predator gape width (GW) and height (GH) are reported in Table 4. Solid lines represent the relationship between PL and predator GW for all predators except spotted hake. GH was found to increase at a lesser rate than width in spotted hake and was therefore plotted as the limiting morphometric gape relationship. Dashed lines indicate linear regressions between PL and squid BD 


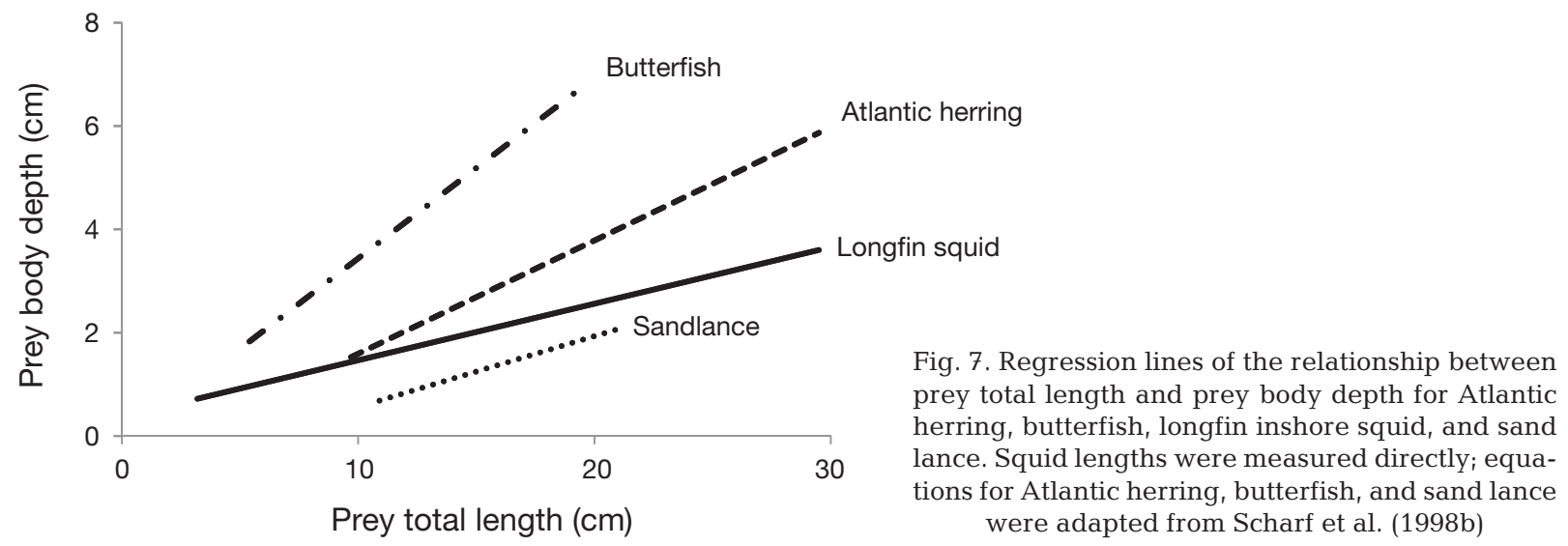

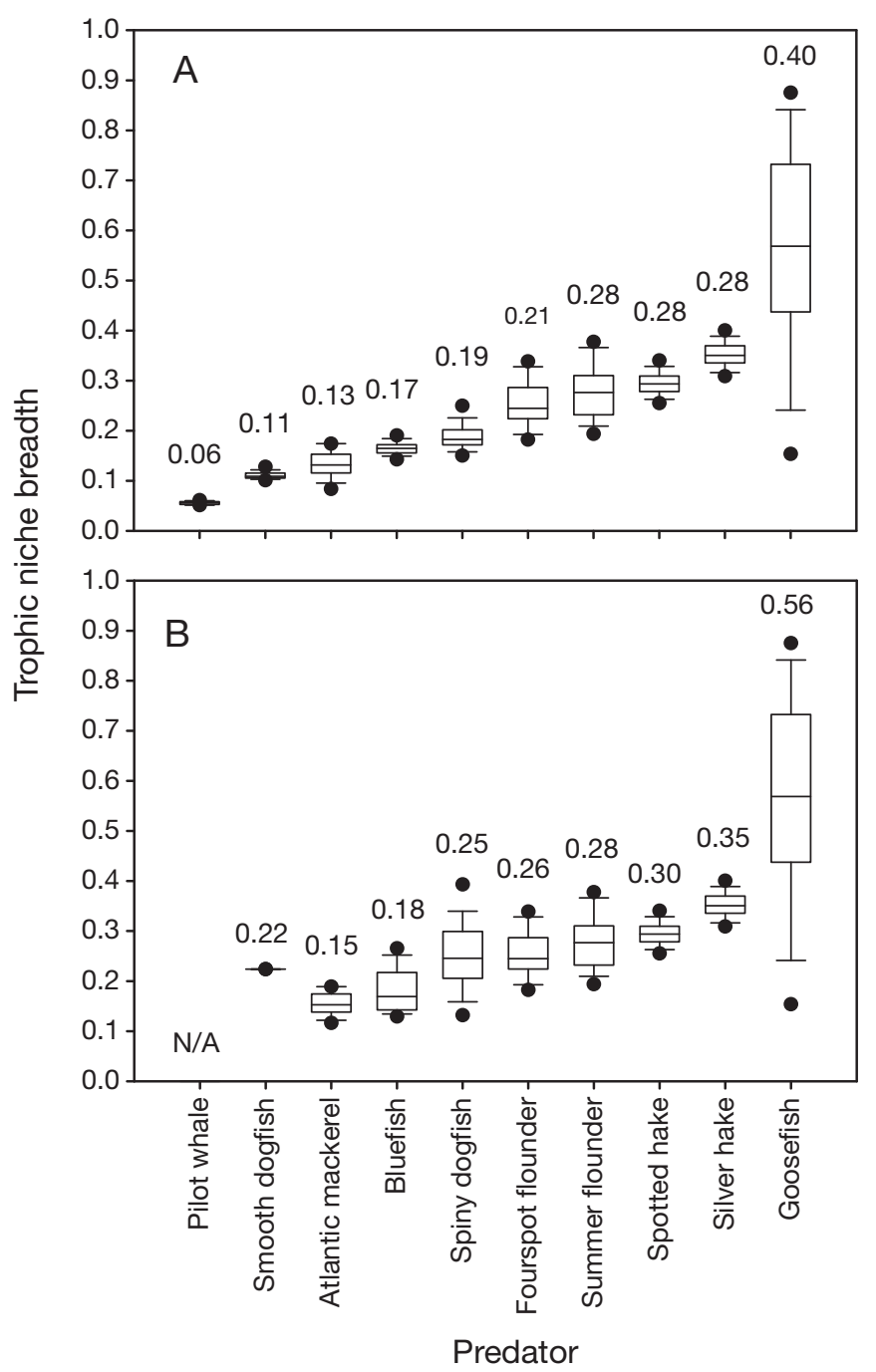

Fig. 8. Measurements of size-based trophic niche breadths for (A) longfin inshore squid and (B) prey fish. Box boundaries represent 25th and 75th percentiles; lines within boxes mark the median. Error bars indicate the 90th and 10th percentiles. Black dots show outliers in the 5th and 95th percentiles. Values indicate the mean trophic niche breadth of each predator.
Comparisons of squid and fish body shapes revealed that Atlantic herring increased BD at greater rates than were observed for squid. This signifies that clupeids outgrow gape-limited predators faster and have a smaller window of predation than squid. The same would also be true of other important prey fish such as butterfish and scup Stenotomus chrysops which are deep bodied and co-occur seasonally with squid in shelf waters (Hendrickson 2005). Squid body shapes were considerably smaller than predator $\mathrm{GH}$, suggesting that predators were not gape limited when foraging on squid (Nilsson \& Bronmark 2000). Despite this, large squid were not common in finfish and elasmobranch diets. Predators also possessed wider sizebased trophic niche breadths for prey fish in comparison to squid, indicating they were not only capable but actually did consume relatively larger prey. Since morphological restrictions were not limiting to predators, availability and behavioral components must be influential in shaping size-based feeding strategies on squid.

Size-based encounter rates between squid and their predators are largely dictated by overall species ranges, activity levels, ontogenetic habitat utilization, and migration patterns. Encounter rates will likely be elevated during the winter and spring seasons when squid and many of their predators aggregate in southern and offshore waters (Staudinger 2006). Unfortunately, diet data were not extensive enough to evaluate seasonal trends that were also species-specific. Diel vertical migration is more pronounced in juvenile squid than in adults (Brodziak \& Hendrickson 1999); accordingly, vertically migrating predators will have the highest encounter rates with juvenile squid. Although juvenile and sub-adult squid were recurrent in finfish and elasmobranch diets, paralarval and small juveniles were rare. Previous studies have also noted this deficiency (Smale 1996, Dawe \& Brodziak 1998). The focus of sampling efforts on demersal predators 
and environments explains to some degree why squid $<5 \mathrm{~cm}$ were only occasionally observed in regional diets. Longfin inshore squid exhibit an ontogenetic descent from surface waters into demersal habitats at $\sim 5 \mathrm{~cm}$ ML (Macy \& Brodziak 2001). Not surprisingly then, Atlantic mackerel, one of the only pelagic species evaluated in this study, had a diet entirely composed of paralarval and juvenile squid. Atlantic mackerel was also the only predator observed to exhibit negative size-selection on squid.

Size distributions from population surveys suggested that squid sizes $>10 \mathrm{~cm}$ ML were relatively scarce in the environment. Despite their scarcity, large squid were favored in the diets of pilot whales and grey seals. Marine mammal diets often reflect considerably wider ranges of cephalopod sizes and species and may be more reliable indicators of cephalopod population distributions in comparison to conventional survey gears (Clarke 2006). Previous work conducted in the northeast Atlantic found that 13 species of toothed whales and 2 species of tunas selected for larger prey than were locally abundant (MacLeod et al. 2006, Ménard et al. 2006). Mean squid lengths reported in the diets of harbor seals in the Gulf of Maine were also quite large (Williams 1999). These accounts provide mounting evidence that marine mammals and large pelagics target larger squid than are normally found in the diets of demersal shelf predators.

\section{Sampling biases}

Data on squid population and predator diet were primarily obtained from bottom-trawl surveys conducted in continental shelf waters. This method of sampling likely underrepresented large squid capable of outswimming nets, prevalent at other depths in the water column, and those that inhabit open ocean envi- ronments (Brodziak \& Hendrickson 1999, Macy \& Brodziak 2001, Hendrickson 2004). Sampling biases may also have influenced predator-prey size data. Data on food habits collected as part of the National Marine Fisheries Service (NMFS) bottom-trawl surveys identify squid from whole specimens and beaks, when possible, and length measurements were made only from intact specimens or pens. Species is not usually determined from pens, and the lower rostral lengths of the lower beaks were not measured as part of NMFS survey protocols. These methods decrease the total number of species-specific squid lengths in diet analyses. Perhaps most importantly, small squid degrade faster in predator stomachs in comparison to large squid; therefore, small squid will more often be recovered in a highly digested state, and the methods of collection noted above lead to underrepresentation of small body sizes (Santos et al. 2001).

Because our study compiled diet data from several sources, different methods were employed to collect prey length data. Sampling of marine mammal diets was more opportunistic than for fish predators. Pilot whale diets were derived from individuals that had been killed incidentally or stranded. It is uncertain if diets from these individuals were representative of healthy animals and the greater population (Gannon \& Waples 2004). Grey seal diets were determined from scat and could not be traced back to specific individuals. In both pilot whales and grey seals, lower rostral lengths of the lower beaks were used to reconstruct original body size using the equations provided by Staudinger et al. (2009). Estimating original length from digested remains can be subject to back-calculation errors, and beaks that are highly digested may be eroded by digestion. To compensate for digestion effects, beaks recovered from grey seal scat were adjusted using a digestion coefficient (Grellier \& Hammond 2006).
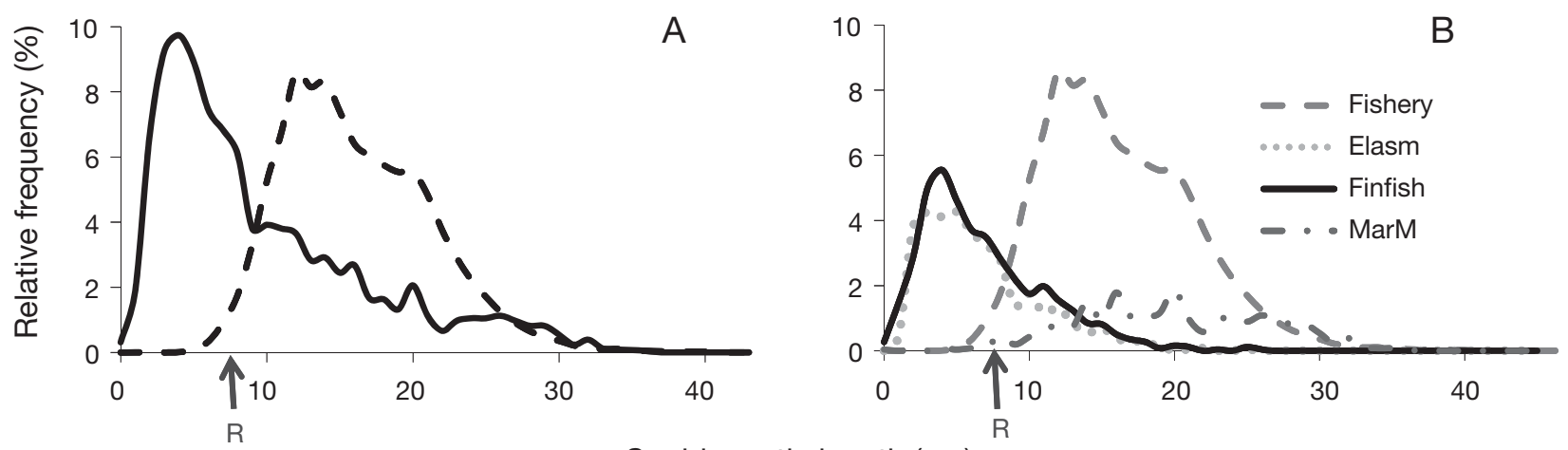

Squid mantle length $(\mathrm{cm})$

Fig. 9. Relative frequency distributions of longfin inshore squid consumed by (A) all predators (solid lines) and harvested by the commercial fishing industry (dashed lines) and (B) major predator assemblages. Groups analyzed included the commercial fishery (Fishery), elasmobranchs (Elasm), finfish (Finfish) and marine mammals (MarM). Arrows and 'R's indicate the sizes at which longfin $(8 \mathrm{~cm} \mathrm{ML})$ recruit into the commercial fishery 


\section{Impacts of fishing pressure}

Finfish and elasmobranch predation was focused primarily on pre-recruit squid, suggesting that overlap with the fishing industry was low. Since commercial landings data may not include biomass removed as bycatch, it is possible that size-based removals of prerecruit squid may be higher than indicated in our analyses (Hall et al. 2000). The observed differences in size-based feeding patterns among predator taxa revealed that marine mammals had the highest overlap and therefore the greatest potential for conflict with the commercial fishing industry. Marine mammals have high energetic demands and are often specialized in their feeding ecology (MacLeod et al. 2006); however, foraging habits are also strongly associated with prey availability and seasonal changes (Andersen et al. 2007). Unfortunately, our results were limited to general depictions of size-based reliance on squid populations; to fully assess competition for squid resources between predators and the fishery, higher seasonal and spatial resolution is needed.

Fishing has eroded the predation landscape by decreasing the prevalence of larger body sizes in exploited populations (Jennings \& Reynolds 2007). All of the fish and elasmobranch species examined here are harvested commercially or caught incidentally by fishing gear. Maximum body sizes of the 9 fish species evaluated using quantile regression analyses were from 20 to $50 \mathrm{~cm}$ smaller than their reported maximum sizes (Table 5). Information on squid-predator bodysize relationships became scarcer for all species with increasing predator body size. This is almost certainly due to the low frequency of large individuals in the ecosystem rather than from diminishing predation rates on squid. Predators that were found to rapidly increase the maximum size of squid in their diets and have the potential to attain substantially larger body sizes than were common over the past several decades (e.g. bluefish, summer flounder) will likely increase their predatory demand on adult squid if population size-structure becomes less truncated. Increased abundance of large fish may also lead to heightened competition with fisheries for adult squid.

Commercial fisheries have increasingly targeted mid-trophic level species including squid to supplement or replace the yields lost from traditional fisheries, such as groundfish and large pelagics (Pauly et al. 1998, Essington et al. 2006). Squid biomass is believed to be artificially inflated due to a release from predatory demand from depressed populations of higher level predators (Caddy \& Rodhouse 1998, Duplisea \& Castonguay 2006). If this is true, fisheries have been taking advantage of excess biomass specifically in the adult component of squid populations that may no longer be in surplus if predator population structure and abundance are recovered under current rebuilding efforts.

Species such as squid that serve as forage to higher level predators and form the 'waists' of marine food webs dictate the dynamic properties of the surrounding food web (Rice 1995). Key forage species have been found to be most sensitive to overfishing at high levels of predation (Collie \& Gislason 2001). Because squid are known to be important mid-trophic level species, target harvest rates and long-term potential yields have been set using precautionary approaches (Brodziak 1998). However, fisheries management plans generally do not include estimates of natural mortality rates on pre-recruits in setting biological reference points (BRPs) and total mortality thresholds (Collie \& Gislason 2001). Furthermore, single-species management plans fail to consider trophic interactions and do not account for changes in predator population structure (Buckel et al. 1999, Pikitch et al. 2004). Because large predators have been functionally absent from the community for several decades, it is uncertain how stock rebuilding will influence predation on squid populations. For example, harvesting adult squid could result in increased survival of pre-recruit squid due to reductions in density-dependent mortality rates. Although intraspecific predation was not included in our analyses, cannibalism within longfin squid populations can be considerable (Macy 1982, Dawe 1988). A similar scenario has been suggested for walleye pollock Theragra chalcogramma and its predators in the eastern Bering Sea (Livingston 1993).

\section{CONCLUSIONS}

Over the past 50 yr the northwest Atlantic has undergone profound shifts in species abundance and composition and is considered one of the most overfished marine ecosystems in the world (Link \& Garrison 2002,

Table 5. Historical and sampled maximum fish lengths ( $\left.\mathrm{L}_{\max }\right)$. Historical lengths were reported by Froese \& Pauly (2008) and Collette \& Klein-MacPhee (2002)

\begin{tabular}{|lcc|}
\hline Species & Historical $\mathrm{L}_{\text {Max }}(\mathrm{cm})$ & Sampled $\mathrm{L}_{\text {Max }}(\mathrm{cm})$ \\
\hline Atlantic mackerel & 60 & 38 \\
Bluefish & 130 & 77 \\
Fourspot flounder & 45 & 43 \\
Goosefish & 120 & 101 \\
Silver hake & 76 & 41 \\
Smooth dogfish & 150 & 123 \\
Spiny dogfish & 160 & 110 \\
Spotted hake & 42 & 40 \\
Summer flounder & 94 & 74 \\
\hline
\end{tabular}


Briggs 2008). Depletion of higher level predators and the prevalence of fishing down the food web are more common in the North Atlantic than in other oceans (Essington et al. 2006). This will be increasingly important as the demographic structure in predator populations is rebuilt. Even if management efforts are not successful in recovering large predators, knowledge of size-based feeding strategies will be useful in predicting the responses of existing populations to exploitation as well as seasonal, annual, and decadal shifts in environmental conditions. Taken as a whole or in parts, the information presented in this study can be used to expand single-species management plans into more holistic multispecies and ecosystem-based approaches.

Acknowledgements. Funding for this study was provided by the Woods Hole Oceanographic Institution Sea Grant Program and the Massachusetts Marine Fisheries Institute. We are grateful to J. Link and the staff of the NEFSC for granting access to, and organization of, the food habits database. This manuscript was greatly improved by additional diet data sets provided by D. Gannon, N. Kohler, K. Ampela, and B. Chase; population and commercial catch data provided by W. Kramer, L. Jacobson, and L. Hendrickson of the NEFSC; and help from S. Lucey in measuring predator gape lengths and squid specimens. We thank S. Cadrin, J. Podos, and B. Letcher for their support throughout the course of this study and their helpful comments on earlier drafts of the manuscript.

\section{LITERATURE CITED}

Andersen SM, Teilmann J, Harders PB, Hansen EH, Hjøllund D (2007) Diet of harbour seals and great cormorants in Limfjord, Denmark: interspecific competition and interaction with fishery. ICES J Mar Sci 64:1235-1245

Azarovitz TR (1981) A brief historical review of the Woods Hole laboratory trawl study time series. In: Doubleday WG, Rivard D (eds) Bottom trawl surveys. Can Spec Publ Fish Aquat Sci 58:62-67

Baum JK, Myers RA, Kehler DG, Worm B, Harley SJ, Doherty PA (2003) Collapse and conservation of shark populations in the northwest Atlantic. Science 299:389-392

Bax NJ (1998) The significance and prediction of predation in marine fisheries. ICES J Mar Sci 55:997-1030

Beauchamp DA, Wahl D, Johnson BM (2007) Predator-prey interactions. In: Guy CS, Brown ML (eds) Analysis and interpretation of inland fisheries data. American Fisheries Society, Bethesda, MD, p 765-842

Bethea DM, Buckel JA, Carlson JK (2004) Foraging ecology of the early life stages of four sympatric shark species. Mar Ecol Prog Ser 268:245-264

Briggs JC (2008) The North Atlantic Ocean: need for proactive management. Fisheries (Bethesda, Md) 33:180-185

Brodziak J (1998) Revised biology and management of longfinned squid (Loligo pealeii) in the northwest Atlantic. CCOFI Rep 39:61-70

Brodziak J, Hendrickson L (1999) An analysis of environmental effects on survey catches of squids Loligo pealeii and Illex illecebrosus in the northwest Atlantic. Fish Bull 97: $9-24$
Brooks JL, Dodson SI (1965) Predation, body size, and composition of plankton. Science 150:28-35

Buckel JA, Fogarty MJ, Conover DO (1999) Mutual prey of fish and humans: a comparison of biomass consumed by bluefish, Pomatomus saltatrix, with that harvested by fisheries. Fish Bull 97:776-785

Caddy JF, Rodhouse PG (1998) Cephalopod and groundfish landings: evidence for ecological change in global fisheries? Rev Fish Biol Fish 8:431-444

Cade BS, Noon BR (2003) A gentle introduction to quantile regression for ecologists. Front Ecol Environ 1:412-420

Cade BS, Terrell JW, Schroeder RL (1999) Estimating effects of limiting factors with regression quantiles. Ecology 80 : $311-323$

Chase B (2002) Differences in diet of Atlantic bluefish tuna (Thunnus thynnus) at five seasonal feeding grounds on the New England continental shelf. Fish Bull 100:168-180

Claessen D, Van Oss C, De Ross AM, Persson L (2002) The impact of size-dependent predation on population dynamics and individual life history. Ecology 83:1660-1675

Clarke MR (1986) A handbook for the identification of cephalopod beaks. Clarendon Press, Oxford

> Clarke MR (1996) Cephalopods as prey. III. Cetaceans. Philos Trans R Soc Lond B Biol Sci 351:1053-1065

Clarke MR (2006) Oceanic cephalopod distribution and species diversity in the eastern north Atlantic. Arquipélago. Life Mar Sci 23A:27-46

Collette BB, Klein-MacPhee G (2002) Bigelow and Schroeder's fishes of the Gulf of Maine, 3rd edn (revised). Smithsonian Institution Press, Washington, DC

Collie JS, Gislason H (2001) Biological reference points for fish stocks in a multispecies context. Can J Fish Aquat Sci 58:2167-2176

> Dawe EG (1988) Length-weight relationships for short-finned squid in Newfoundland and the effect of diet on condition and growth. Trans Am Fish Soc 117:591-599

Dawe EG, Brodziak JKT (1998) Trophic relationships, ecosystem variability, and recruitment. In: Rodhouse PG, Dawe EG, O'Dor RK (eds) Squid recruitment dynamics. The genus Illex as a model. The commercial Illex species. Influences on variability. Food and Agriculture Organization of the United Nations Fisheries Technical Paper. No. 376. Rome, FAO. p 125-156

Dorner H, Wagner A (2003) Size-dependent predator-prey relationships between perch and their fish prey. J Fish Biol 62:1021-1032

Duplisea DE (2005) Running the gauntlet: the predation environment of small fish in the northern Gulf of St. Lawrence, Canada. ICES J Mar Sci 62:412-416

Duplisea DE, Castonguay M (2006) Comparison and utility of different size-based metrics of fish communities for detecting fishery impacts. Can J Fish Aquat Sci 63:810-820

Essington TE, Beaudreau AH, Wiedenmann J (2006) Fishing through marine food webs. Proc Natl Acad Sci USA 103:3171-3175

FAO (2007) Total production 1950-2005. FAO homepage (former FAO yearbook of fisheries statistics 'catches and landings'). http://www.fao.org/fishery/publications/yearbooks/

Froese R, Pauly D (2008) FishBase. www.fishbase.org, version $(04 / 2008)$

Gannon DP, Waples DM (2004) Diets of coastal bottlenose dolphins from the U.S. mid-Atlantic coast differ by habitat. Mar Mamm Sci 20:527-545

Gannon DP, Read AJ, Craddock JE, Fristrup KM, Nicolas JR (1997) Feeding ecology of long-finned pilot whales Globicephala melas in the western North Atlantic. Mar Ecol Prog Ser 148:1-10 
Grellier K, Hammond PS (2006) Robust digestion and passage rate estimates for hard parts of grey seal (Halichoerus grypus) prey. Can J Fish Aquat Sci 63:1982-1998

Hall MA, Alverson DL, Metuzals KI (2000) By-catch: problems and solutions. Mar Pollut Bull 41:204-219

Hanlon RT, Messenger JB (1996) Cephalopod behavior. Cambridge University Press, Cambridge

Hendrickson LC (2004) Population biology of northern shortfin squid (Illex illecebrosus) in the northwest Atlantic ocean and initial documentation of a spawning site in the mid-Atlantic Bight (USA). ICES J Mar Sci 61:252-266

Hendrickson L (2005) Effectiveness of a square-mesh escape panel in reducing finfish bycatch in a small-mesh bottom trawl used in the longfin inshore squid (Loligo pealeii) fishery. US Dep Commer, Northeast Fish Sci Cent Ref Doc. 05-05; $37 \mathrm{p}$

Jackson JBC, Kirby MX, Berger WH, Bjorndal KA and others (2001) Historical overfishing and the recent collapse of coastal ecosystems. Science 293:629-638

Jacobson LD (2005) Essential fish habitat source document: longfin inshore squid, Loligo pealeii, life history and habitat characteristics, 2nd edn. NOAA Technical Memorandum NMFS-NE 193; $42 \mathrm{p}$

Jennings S, Reynolds JD (2007) Body size, exploitation and conservation of marine organisms. In: Hildrew A, Raffaelli D, Edmonds-Brown R (eds) Body size: the structure and function of aquatic ecosystems. Cambridge University Press, Cambridge, p 266-285

Juanes F (1994) What determines prey selectivity in piscivorous fishes? In: Stouder DJ, Fresh KL, Feller RJ (eds) Theory and application in fish feeding ecology. University of South Carolina Press, Columbia, SC, p 79-100

Juanes F (2003) The allometry of cannibalism in piscivorous fishes. Can J Fish Aquat Sci 60:594-602

Juanes F, Conover DO (1995) Size-structured piscivory: advection and the linkage between predator and prey recruitment in young-of-the-year bluefish. Mar Ecol Prog Ser 128:287-304

Juanes F, Buckel JA, Scharf FS (2002) Feeding ecology of piscivorous fishes. In: Hart PJB, Reynolds JD (eds) Handbook of fish biology and fisheries. Blackwell Science, Malden, MA, p 267-283

Kohler NE (1987) Aspects of the feeding ecology of the blue shark, Prionace glauca in the western North Atlantic. PhD dissertation, University of Rhode Island, Kingston, RI

- Lee PG (1994) Nutrition of cephalopods: fueling the system. Mar Freshw Behav Physiol 25:35-51

> Link JS, Garrison LP (2002) Changes in piscivory associated with fishing induced changes to the finfish community on Georges Bank. Fish Res 55:71-86

Livingston PA (1993) Importance of predation by groundfish, marine mammals and birds on walleye pollock Theragra chalcogramma and pacific herring Clupea pallasi in the eastern Bering Sea. Mar Ecol Prog Ser 102:205-215

MacLeod CD, Santos MB, Lopez A, Pierce GJ (2006) Relative prey size consumption in toothed whales: implications for prey selection and level of specialisation. Mar Ecol Prog Ser 326:295-307

Macy WK (1982) Feeding patterns of the long-finned squid, Loligo pealeii, in New England waters. Biol Bull 162: 28-38

- Macy WK, Brodziak JKT (2001) Seasonal maturity and size at age of Loligo pealeii in waters of southern New England. ICES J Mar Sci 58:852-864

Manderson JP, Phelan BA, Bejda AJ, Stehlik LL, Stoner AW (1999) Predation by striped searobin (Prionotus evolans, Triglidae) on young-of-the-year winter flounder (Pseudo- pleuronectes americanus, Walbaum): examining prey size selection and prey choice using field observations and laboratory experiments. J Exp Mar Biol Ecol 242:211-231

- Ménard F, Labrune C, Shin YJ, Asine AS, Bard FX (2006) Opportunistic predation in tuna: a size-based approach. Mar Ecol Prog Ser 323:223-231

> Mittelbach GG, Persson L (1998) The ontogeny of piscivory and its ecological consequences. Can J Fish Aquat Sci 55: $1454-1465$

Myers RA, Worm B (2003) Rapid worldwide depletion of predatory fish communities. Nature 423:280-283

NEFC (Northeast Fisheries Center Survey Working Group) (1988) An evaluation of the Bottom Trawl Survey Program of the Northeast Fisheries Center. NOAA Technical Memorandum NMFS-F/NEC-52. Northeast Fisheries Center, Woods Hole, MA, USA

Nilsson PA, Bronmark C (2000) Prey vulnerability to a gapesize limited predator: behavioral and morphological impacts on northern pike piscivory. Oikos 88:539-546

NEFSC (Northeast Fisheries Science Center) (2002) Report of the 34th northeast regional stock assessment workshop (34th SAW): Stock Assessment Review Committee (SARC) consensus summary of assessments. Northeast Fish. Sci. Cent. Ref. Doc. 02-06; 346 p

> Overholtz WJ, Link JS, Suslowicz LE (2000) Consumption of important pelagic fish and squid by predatory fish in the northeastern USA shelf ecosystem with some fishery comparisons. ICES J Mar Sci 57:1147-1159

> Packard A (1972) Cephalopods and fish: the limits of convergence. Biol Rev Camb Philos Soc 47:241-307

Pauly D (1998) Why squid, though not fish, may be better understood by pretending they are. S Afr J Mar Sci 20: 47-58

Pauly D, Christensen V, Dalsgaard J, Froese R, Torres F (1998) Fishing down marine food webs. Science 279: 860-863

Pauly D, Christensen V, Guenette S, Pitcher TJ and others (2002) Towards sustainability in world fisheries. Nature 418:689-695

Pearre S (1986) Ratio-based trophic niche breadths of fish, the Sheldon Spectrum, and the size-efficiency hypothesis. Mar Ecol Prog Ser 27:299-314

Peters RH (1983) The ecological implications of body size. Cambridge University Press, New York

> Piatkowski U, Pierce GJ, Morais da Cunha M (2001) Impact of cephalopods in the food chain and their interaction with the environment and fisheries: an overview. Fish Res 52: $5-10$

Pierce PJ, Guerra A (1994) Stock assessment methods used for cephalopod fisheries. Fish Res 21:255-285

Pikitch EK, Santora C, Babcock EA, Bakun A and others (2004) Ecosystem-based fishery management. Science 305:346-347

Rice J (1995) Food web theory, marine food webs, and what climate change may do to northern marine fish populations. In: Beamish RJ (ed) Climate change and northern fish populations. Can Spec Publ Fish Aquat Sci 121: 561-568

Rice J, Gislason H (1996) Patterns of change in the size spectra of numbers and diversity of the North Sea fish assemblage, as reflected in surveys and models. ICES J Mar Sci 53:1214-1225

Santos MB, Clarke MR, Pierce GJ (2001) Assessing the importance of cephalopods in the diets of marine mammals and other top predators: problems and solutions. Fish Res 52: 121-139

SAS (2003) SAS. SAS Institute, Carey, NC 
Scharf FS, Juanes F, Sutherland M (1998a) Inferring ecological relationships from the edges of scatter diagrams: comparison of regression techniques. Ecology 79:448-460

Scharf FS, Yetter RM, Summers AP, Juanes F (1998b) Enhancing diet analyses of piscivorous fishes in the northwest Atlantic through identification and reconstruction of original prey sizes from ingested remains. Fish Bull 96:575-588

Scharf FS, Juanes F, Rountree RA (2000) Predator size-prey size relationships of marine fish predators: interspecific variation and effects of ontogeny and body size on trophicniche breadth. Mar Ecol Prog Ser 208:229-248

Scharf FS, Buckel JA, McGinn PA, Juanes F (2003) Vulnerability of marine forage fishes to piscivory: effects of prey behavior on susceptibility to attack and capture. J Exp Mar Biol Ecol 294:41-59

Sih A, Christensen B (2001) Optimal diet theory: When does it work, and when and why does it fail? Anim Behav 61: 379-390

Smale MJ (1996) Cephalopods as prey. IV. Fishes. Philos Trans R Soc Lond B Biol 351:1067-1081

Sokal RR, Rohlf FJ (1995) Biometry, 3rd edn. W. H. Freeman, New York

Editorial responsibility: Nicholas Tolimieri,

Seattle, Washington, USA
Staudinger MD (2006) Seasonal and size-based predation on two species of squid by four fish predators on the northwest Atlantic continental shelf. Fish Bull 104: 605-615

Staudinger MD, Juanes F, Carlson S (2009) Reconstructing body size from ingested remains and estimating total length in two species of squid from the northwest Atlantic. Fish Bull 107:101-105

Stephens DW, Krebs JR (1986) Foraging theory. Princeton University Press, Princeton, NJ

Stillwell CE, Kohler NE (1982) Food, feeding habits, and estimates of daily ration of the shortfin mako (Isurus oxyrinchus) in the northwest Atlantic. Can J Fish Aquat Sci 39:407-414

Ward P, Myers RA (2005) Shifts in open-ocean fish communities coinciding with the commencement of commercial fishing. Ecology 86:835-847

Williams AS (1999) Prey selection by harbor seals in relation to fish taken by the Gulf of Maine sink gillnet fishery. MS thesis, University of Maine, Orono, ME

Zar JH (1984) Biostatistical analysis, 4th edn. Prentice Hall, Englewood Cliffs, NJ

Submitted: April 17, 2009; Accepted: September 25, 2009 Proofs received from author(s): January 12, 2010 